\title{
Multi-Functional Perylenediimide-Based Cathode Interfacial Materials for High-Performance Inverted Perovskite Solar Cells
}

Tao Wu, ${ }^{\mathrm{a}}$ Daizhe Wang, ${ }^{\mathrm{a}}$ Yi Lu, ${ }^{\text {a }}$ Zhi Zheng, ${ }^{\mathrm{a}}$ Fengyun Guo, ${ }^{\mathrm{a}}$ Tengling Ye, ${ }^{\mathrm{b}, *}$ Shiyong Gao, ${ }^{\mathrm{a}}$ Yong Zhanga,c*

aSchool of Materials Science and Engineering, Harbin Institute of Technology, Harbin 150001, China

${ }^{b}$ School of Chemistry and Chemical Engineering, Harbin Institute of Technology, Harbin 150001, China

'School of Materials Science and Engineering, Zhengzhou University, Zhengzhou 450001, China

E-mail: yongzhang@hit.edu.cn; ytl@hit.edu.cn

\section{Experimental Procedures}

\section{Materials}

All chemicals and solvents were purchased from commercials and used directly without further purification except mention. Compound 1 and M3 (PDIN) were prepared according to the reported literatures from our group ${ }^{1}$. Compound 2 was prepared according to the reported literatures ${ }^{2}$. 

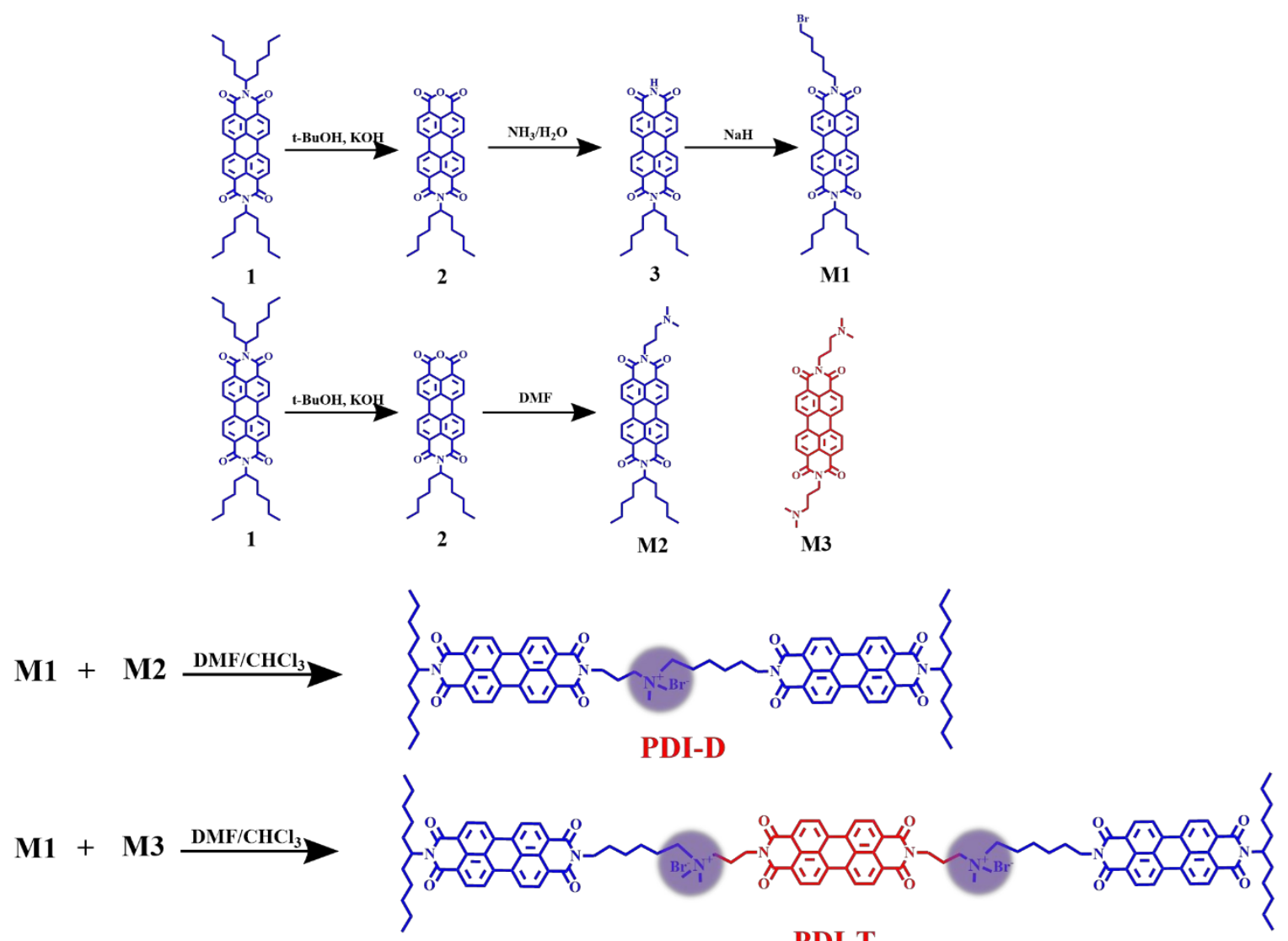

PDI-T

Scheme S1. Synthetic route of PDI-D and PDI-T

\section{Synthesis of compound 3}

To a compound $2(1.1 \mathrm{~g}, 2.0 \mathrm{mmol})$ and $25 \%$ ammonium hydroxide solution $(1 \mathrm{~mL}, 10.0$ mmol) in butanol $(50 \mathrm{~mL})$, the mixture was stirred at $50{ }^{\circ} \mathrm{C}$ for $3 \mathrm{~h}$, and then warmed to 80 ${ }^{\circ} \mathrm{C}$ stirring overnight. After cooling to room temperature, the mixture was poured into $\mathrm{NaCl}$ solution and was extracted with dichloromethane (DCM). The combined organic phases were dried over anhydrous $\mathrm{MgSO}_{4}$ and concentrated to obtain the crude product. The product was further purified by column chromatography on silica gel using DCM:MeOH (50:1) as the eluent, affording a dark red solid (578 mg, 52\%). ${ }^{1} \mathrm{H} \mathrm{NMR}\left(500 \mathrm{MHz}, \mathrm{CDCl}_{3}\right.$,

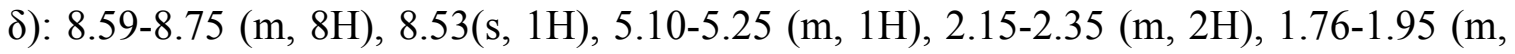
2H), 1.10-1.40 (m, 16H), $0.88(\mathrm{t}, 6 \mathrm{H})$. 


\section{Synthesis of compound M1}

To a suspension of compound $3(556 \mathrm{mg}, 1 \mathrm{mmol})$ in dry DMF $(100 \mathrm{~mL})$ at $0{ }^{\circ} \mathrm{C}$ was added $\mathrm{NaH}$ (36mg, $1.5 \mathrm{mmol}$ ). The mixture was stirred for $30 \mathrm{~min}$, and then the 1,6dibromohexane (366 mg, $1.5 \mathrm{mmol}$ ) was added. After the mixture was allowed to warm to room temperature and stirred for $1 \mathrm{~h}$ and then heated at $80{ }^{\circ} \mathrm{C}$ for 3 days. The mixture was slowly poured into $\mathrm{NH}_{4} \mathrm{Cl}$ solution $(100 \mathrm{~mL})$ and extracted with DCM, and the combined organic phases were dried over anhydrous $\mathrm{MgSO}_{4}$ and concentrated to obtain the crude product. The product was then further purified by column chromatography on silica gel using DCM as the eluent afford a red solid (518 mg, 75\%). ${ }^{1} \mathrm{H} \mathrm{NMR}\left(500 \mathrm{MHz}, \mathrm{CDCl}_{3}\right.$,

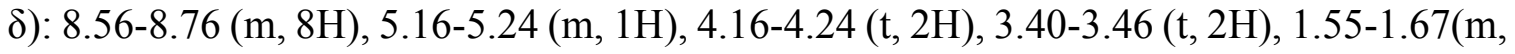
$6 \mathrm{H}), 1.80-1.90(\mathrm{~m}, 2 \mathrm{H}), 1.10-1.40(\mathrm{~m}, 16 \mathrm{H}), 0.88(\mathrm{t}, 6 \mathrm{H})$.

\section{Synthesis of compound M2}

To a suspension of the compound $2(279 \mathrm{mg}, 0.5 \mathrm{mmol})$ in dry DMF $(25 \mathrm{~mL})$ and 1,4dioxene $(25 \mathrm{~mL}), 3$-(dimethylamino)-1-propylamine $(77 \mathrm{mg}, 0.75 \mathrm{mmol})$ was added into the flask in one portion under nitrogen atmosphere. Then the mixture was warmed to $80{ }^{\circ} \mathrm{C}$ and stirring for 1 days. After cooling to room temperature, the mixture was poured into $\mathrm{NaCl}$ solution and was extracted with DCM. The combined organic phases were dried over anhydrous $\mathrm{MgSO}_{4}$ and concentrated to obtain the crude product. The product was then further purified by column chromatography on silica gel using DCM:MeOH (10:1) as the eluent afford a dark red solid (282 mg, 88\%). ${ }^{1} \mathrm{H}$ NMR (500 MHz, $\left.\mathrm{CDCl}_{3}, \delta\right): 8.56-$ $8.76(\mathrm{~m}, 8 \mathrm{H}), 5.16-5.24(\mathrm{~m}, 1 \mathrm{H}), 4.20-4.30(\mathrm{t}, 2 \mathrm{H}), 2.40-2.56(\mathrm{t}, 2 \mathrm{H}), 2.25-2.30(\mathrm{~s}, 6 \mathrm{H})$, $1.80-1.90(\mathrm{t}, 2 \mathrm{H}), 1.60-1.70(\mathrm{~m}, 4 \mathrm{H}), 1.10-1.40(\mathrm{~m}, 12 \mathrm{H}), 0.88(\mathrm{t}, 6 \mathrm{H})$. 


\section{Synthesis of compound PDI-D}

To a compound M1 (54 mg, $0.075 \mathrm{mmol})$ and compound M2 (45 mg, $0.07 \mathrm{mmol})$ in dry DMF $(10 \mathrm{~mL})$ and chloroform $(10 \mathrm{~mL})$, the mixture was stirred at $50{ }^{\circ} \mathrm{C}$ for 3 days, and then the solution was poured into $100 \mathrm{~mL}$ stirring ethyl acetate solution, the solids are centrifuged and washed with ethyl acetate several times until the solution becomes colorless, the crude product is dried by vacuum drying oven and afford a black-red solid (84 mg, 89\%).

\section{Synthesis of compound PDI-T}

To a compound M1 (108 mg, $0.15 \mathrm{mmol})$ and compound $\mathbf{M 3}(40 \mathrm{mg}, 0.07 \mathrm{mmol})$ in dry DMF $(10 \mathrm{~mL})$ and chloroform $(10 \mathrm{~mL})$, the mixture was stirred at $50{ }^{\circ} \mathrm{C}$ for 3 days, and then the solution was poured into $100 \mathrm{~mL}$ stirring ethyl acetate solution, the solids are centrifuged and washed with ethyl acetate several times until the solution becomes colorless, the crude product is dried by vacuum drying oven and afford a purple-red solid (128 mg, 92\%).

\section{Material characterizations}

${ }^{1} \mathrm{H}$ NMR spectra were measured on a Bruker-AV 500MHz with d-chloroform as the solvent and trimethylsilane as the internal reference. UV-visible absorption spectra were measured via Beijing Purkinje General-TU-1901 spectrophotometer. Cyclic voltammetry （come from our research group) was performed on a CH Instruments CHI660E electrochemical workstation with a three-electrode system in $0.1 \mathrm{M} \mathrm{PF}_{6}$ acetonitrile solution at a scan rate of $40 \mathrm{mV} / \mathrm{s}$. ITO with sample film was used as the working electrode. A Pt wire was used as the counter electrode and $\mathrm{Ag} / \mathrm{AgCl}$ was used as the reference electrode. 
Ferrocene/ferrocenium redox couple was used as the external standard and its redox potential is $0.36 \mathrm{~V}$ vs. $\mathrm{Ag} / \mathrm{AgCl}$. The LUMO energy levels were calculated from the onset of the reduction potentials using the following equations: $\mathrm{E}_{\mathrm{HOMO}}=-\mathrm{e}\left(\varphi_{\mathrm{red}}+4.44\right)(\mathrm{eV})$; $\mathrm{E}_{\mathrm{LUMO}}=E_{\text {opt }}^{g}+\mathrm{E}_{\mathrm{HOMO}}(\mathrm{eV})$. Atomic force microscopy (AFM) images were obtained using a NanoMan VS microscope in the tapping mode. SEM images were obtained with Merlin Compact. ESR (State Key Laboratory of Luminescent Materials and Devices, South China University of Technology) spectra were recorded on a JEOL JES-FA200 ESR spectrometer (300 K, $9.063 \mathrm{GHz}, \mathrm{X}$-band). The steady-state PL spectra was performed by a $\mathrm{He}-\mathrm{Cd}$ ultraviolet laser at $405 \mathrm{~nm}$ using Micro-PL Spectrometer-Lab-RAM HR800. UPS (PHI CHINA) images were obtained using a PHI5000 Versa Probe III (X-ray source: Al Ka mono $(1486.6 \mathrm{eV}))$.

\section{Device fabrication and characterization}

The etched ITO glass was rinsed with deionized water and followed by ultrasonic cleaning with acetone and isopropanol twice. Then, ITO substrates were treated with oxygen plasma for 10 mins. Afterward, $3.5 \mathrm{mg}$ PTAA and $2 \mathrm{mg}$ Tris(pentafluorophenyl)borane (BCF) were dissolved in $1 \mathrm{~mL}$ chlorobenzene $(\mathrm{CB})$, respectively. After the solutes were completely dissolved, $12 \mathrm{wt} \%$ of BCF was added into the PTAA solution. The BCF-PTAA solution was illuminated for 5 mins under solar simulator $\left(100 \mathrm{~mW} \cdot \mathrm{cm}^{-2}\right)$ and was kept in the dark at room temperature, waiting to be used. PTAA films were spin-coated at 4500 rpms for 25 secs, followed by annealing at $120{ }^{\circ} \mathrm{C}$ for $10 \mathrm{mins}$. The perovskite light absorption layer was prepared by the following typical one-step method. (FAPbI 3 : $\mathrm{MAPbBr}_{3}=83: 17$ was dissolved in VDMF: VDMSO $=5: 1$, and CsI 5\% was added) was spin-coated on the $1.1 \times 1.5 \mathrm{~cm}^{2}$ ITO/PTAA substrate at $5000 \mathrm{rpm}$ for $35 \mathrm{~s}$. After $10 \mathrm{~s}, 300$ 
$\mu \mathrm{L}$ of anisole is dispensed on the sample. Then, the samples were annealed at $110{ }^{\circ} \mathrm{C}$ for 30 mins. After cooling down to room temperature, a $15 \mathrm{mg} / \mathrm{mL} \mathrm{PC}_{61} \mathrm{BM}$ solution in $\mathrm{CB}$ was spin-coated at $1500 \mathrm{rpms}$ for $60 \mathrm{~s}$. Then $0.5-9.0 \mathrm{mg} / \mathrm{mL}$ PDI-D or PDI-T (dissolved in 2,2,2-trifluoroethanol) was spin-coated on $\mathrm{PC}_{61} \mathrm{BM}$ at $2500 \mathrm{rpms}$ for $1 \mathrm{~min}$. Lastly, $100 \mathrm{~nm}$ Ag film was thermally evaporated as a counter electrode under a pressure of $7 \times 10^{-4} \mathrm{~Pa}$, and the active area of the device was $0.04 \mathrm{~cm}^{2}$. Complete fabrication process of PVSCs was done in the glovebox.

The electron-only devices for $\mathrm{PC}_{61} \mathrm{BM}, \mathrm{PC}_{61} \mathrm{BM} / \mathrm{PDI}-\mathrm{D}$ and $\mathrm{PC}_{61} \mathrm{BM} / \mathrm{PDI}-\mathrm{T}$ films were fabricated as follows. The1.5 $\mathrm{M} \mathrm{ZnO}$ precursor solution was spin-coated on the cleaned ITO at $4000 \mathrm{rpm}$ for $30 \mathrm{~s}$ and then annealed at $250{ }^{\circ} \mathrm{C}$ for $30 \mathrm{~min}$. After the films were cooled down, the $15 \mathrm{mg} \mathrm{mL}^{-1}$ PCBM (chlorobenzene solution), PDI-D or PDI-T (2,2,2trifluoroethanol solution ) was spin-coated at $1500 \mathrm{rpm}$ for $60 \mathrm{~s}$ without additional annealing. Finally, $\mathrm{Ca}(20 \mathrm{~nm})$ and $\mathrm{Al}(100 \mathrm{~nm})$ films were evaporated on top of the active layer as the electrode.

The mobility was determined by fitting the dark current to the model of a single carrier SCLC, which is described by the equation:

$$
J=\frac{8}{9} \varepsilon_{0} \varepsilon_{r} \mu_{h} \frac{V^{2}}{d^{3}}
$$

Where $J$ is the current, $\mu_{h}$ is the zero-field mobility, $\varepsilon_{0}$ is the permittivity of free soace, $\varepsilon_{r}$ is the relative permittivity of the material, $d$ is the thickness of the active layer, and $V$ is the effective voltage. 
Conductivity measurements were performed by measuring I-V characteristics between two ITO electrodes using a Keithley 236 source meter. Also, PDI-D and PDI-T films were spincoated on the patterned ITO glass. The conductivity $(\sigma)$ was calculated by the following equation $\sigma=\mathrm{W} /(\mathrm{RLD})$, where $\mathrm{L}$ was the channel length with $15 \mathrm{~mm}$, $\mathrm{W}$ was the channel width $115 \mu \mathrm{m}$, D was the thickness of PDI-D or PDI-T film measured by AFM, and R was the film resistance derived from the slope of the I-V curves.

Table S1 Comparison of the physicochemical properties of the CIM of PDI-D and PDI-T.

\begin{tabular}{cccccccc}
\hline \multirow{2}{*}{ mater } & \multicolumn{2}{c}{$\begin{array}{c}\text { Absorption } \\
(\mathbf{n m})\end{array}$} & HOMO & LUMO & $\mathbf{E}_{\mathbf{g}}$ & Conductivity & Work \\
\cline { 2 - 6 } & $\lambda_{\max }$ & $\lambda_{\text {edg }}$ & $(\mathbf{e V})$ & $(\mathbf{e V})$ & $(\mathbf{e V})$ & $\left(\mathbf{1 0}^{-5} \mathbf{S ~ c m}^{-\mathbf{1}}\right)$ & function \\
& & & & & & & $(\mathbf{e V})$ \\
\hline PDI-D & 499 & 635 & -5.73 & -4.12 & 1.61 & 0.05 & 4.04 \\
PDI-T & 498 & 643 & -5.55 & -3.96 & 1.59 & 1.60 & 3.84 \\
\hline
\end{tabular}

Table S2 The photovoltaic performance of PDI-T device with different thicknesses.

\begin{tabular}{ccccc}
\hline $\begin{array}{c}\text { Thicknesses } \\
(\mathbf{n m})\end{array}$ & $\mathbf{V}_{\mathbf{o c}}$ & $\mathbf{J}_{\mathbf{s e}}$ & $\mathbf{F F}$ & PCE \\
\hline $\mathbf{( m V )}$ & $\left(\mathbf{m A ~ \mathbf { ~ m } ^ { - 2 } )}\right.$ & $\mathbf{( \% )}$ & $\mathbf{( \% )}$ \\
$\mathbf{1 4}$ & 1161 & 22.42 & 80.35 & 20.91 \\
$\mathbf{3 8}$ & 1153 & 22.73 & 80.56 & 21.06 \\
$\mathbf{5 1}$ & 1165 & 22.19 & 77.12 & 19.94 \\
$\mathbf{6 3}$ & 1.58 & 22.08 & 78.30 & 20.02 \\
\hline
\end{tabular}



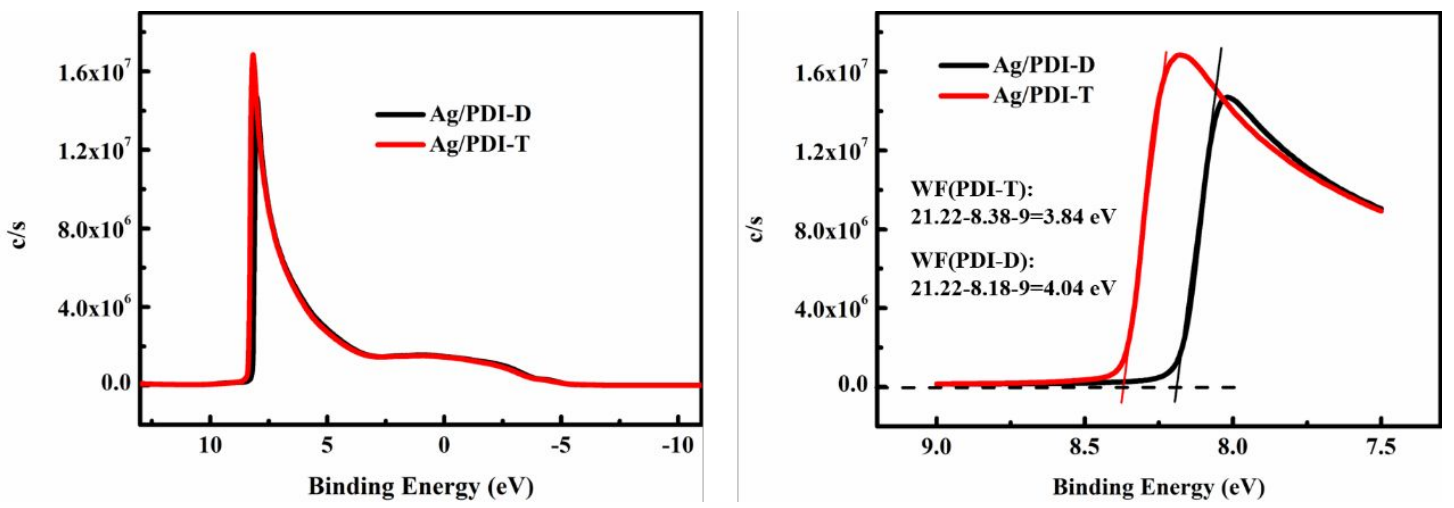

Fig. S1 The UPS of Ag/PDI-D and Ag/PDI-T. (a) is the full image and (b) is the local magnification.

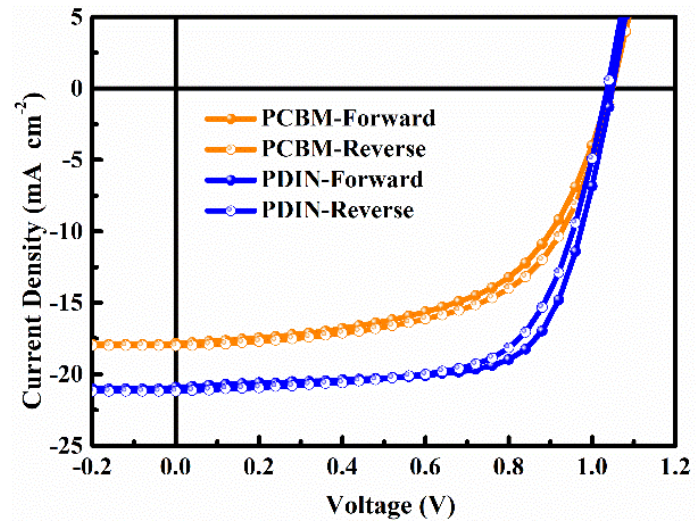

Fig. S2 J-V curves with different scanning directions of without CIL and PDIN incorporated PVSC.

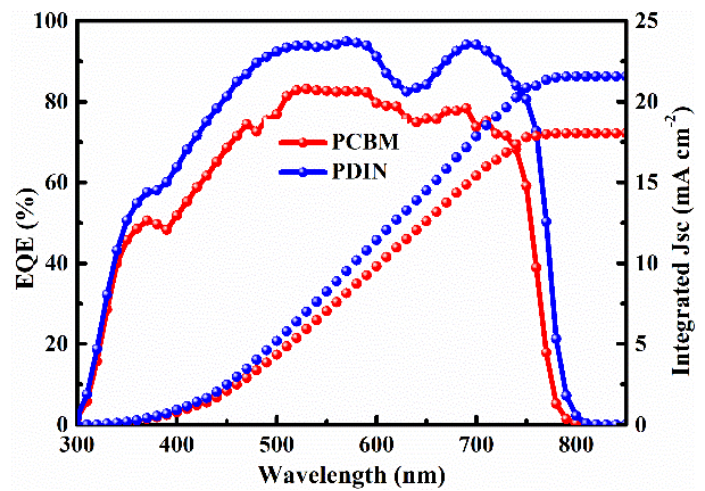

Fig. S3 Corresponding EQE spectra and the integrated Jsc curves of without CIL and PDIN incorporated PVSC. 


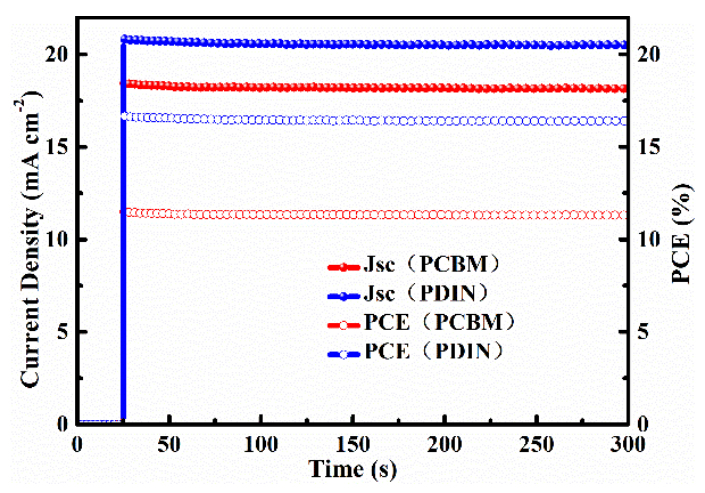

Fig. S4 The stabilized $\mathrm{J}_{\mathrm{sc}}$ and PCE traces for the two devices.

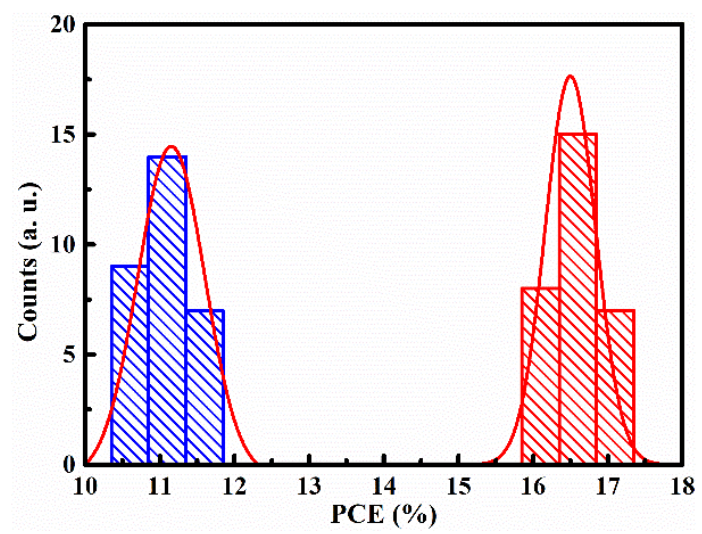

Fig. S5 The statistics of PCE distribution histograms without CIL and PDIN incorporated PVSC.

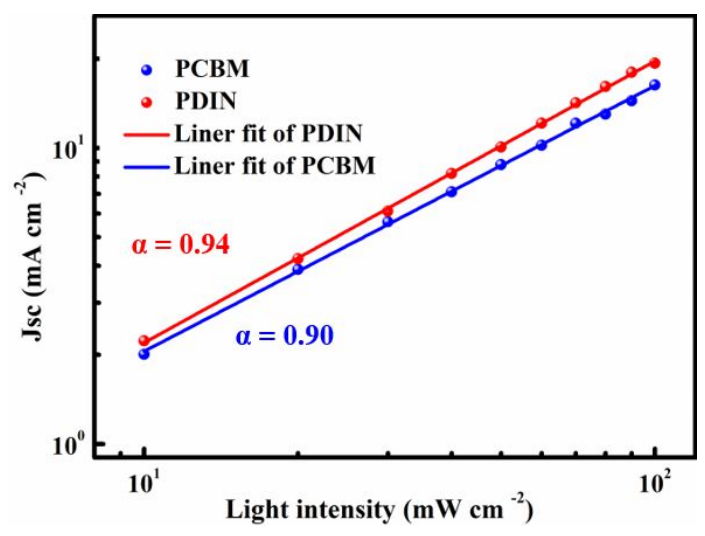

Fig. S6 Corresponding Jsc versus light intensity traces for the two devices (symbols) together with a linear model fitted to the data (solid lines). 


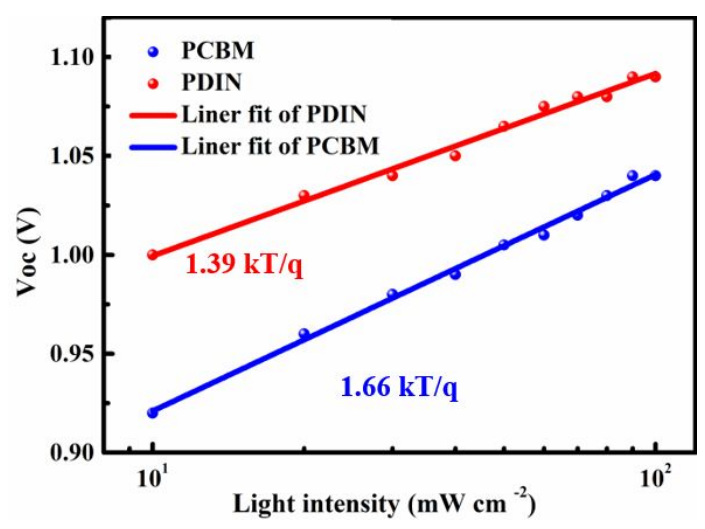

Fig. S7 Corresponding Voc versus light intensity traces for the two devices (symbols) together with a linear model fitted to the data (solid lines).

(a)

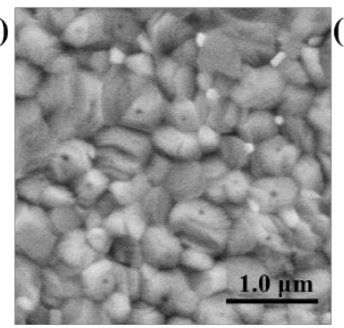

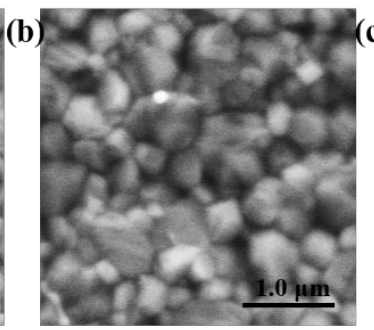

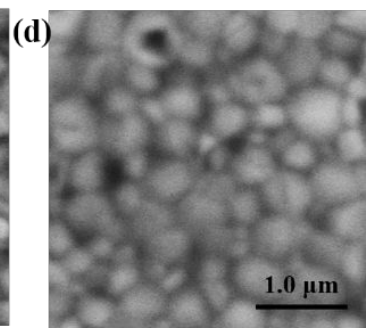

Fig. S8 The SEM top-view images of bare perovskite (a) and that coated with $\mathrm{PC}_{61} \mathrm{BM}(\mathrm{b}) \mathrm{PC}_{61} \mathrm{BM} / \mathrm{PDI}-\mathrm{D}$

(c) or $\mathrm{PC}_{61} \mathrm{BM} / \mathrm{PDI}-\mathrm{T}(\mathrm{d})$.

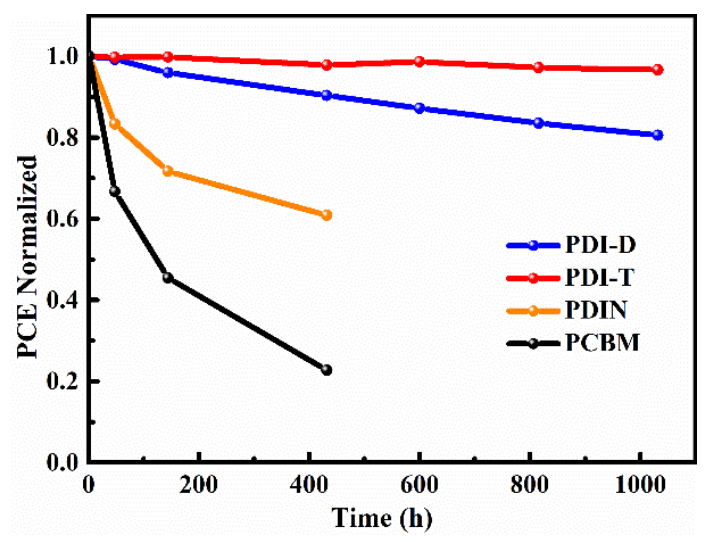

Fig. S9 The stability test of PVSCs with $\mathrm{PC}_{61} \mathrm{BM} / \mathrm{PDI}-\mathrm{D}$ and $\mathrm{PC}_{61} \mathrm{BM} / \mathrm{PDI}-\mathrm{T}$ as the interface layer. 
Table S3 The PCEs with different CIMs for inverted perovskite solar cells in recent years.

\begin{tabular}{|c|c|c|c|c|c|}
\hline Device structure & $\begin{array}{c}\mathrm{J}_{\mathrm{sc}} \\
{[\mathrm{mA}} \\
\left.\mathrm{cm}^{-2}\right]\end{array}$ & $\begin{array}{l}\mathrm{V}_{\mathrm{oc}} \\
{[\mathrm{V}]}\end{array}$ & $\begin{array}{c}\mathrm{FF} \\
{[\%]}\end{array}$ & $\begin{array}{c}\mathrm{PCE} \\
{[\%]}\end{array}$ & Ref. \\
\hline ITO/PEDOT:PSS/perovskite/t-BPTI/C60/BCP/Al & 19.80 & 0.97 & 60.55 & 11.63 & 3 \\
\hline ITO/P3CT-Na/ perovskite /TPE-PDI4/C60/BCP/Ag & 21.98 & 1.05 & 81 & 18.78 & 4 \\
\hline ITO/P3CT-Na/perovskite/Tr-PDI3/C60/BCP/Ag & 22.22 & 1.08 & 83 & 19.83 & 5 \\
\hline ITO/TiO2/PDI $/$ /perovskite/Spiro-OMeTAD/Ag & 23.29 & 1.07 & 79.61 & 19.84 & 6 \\
\hline $\begin{array}{c}\text { ITO/PTAA:F4-TCNQ/PMMA/perovskite } \\
\text { /IDTT2FPDI/PCBM/Bphen/Al }\end{array}$ & 23.9 & 1.10 & 73.8 & 19.4 & 7 \\
\hline ITO/LT-NiO/perovskite/PCBM/PDINO/Ag & 20.57 & 1.11 & 76.5 & 17.5 & 8 \\
\hline ITO/PEDOT:PSS/perovskite/NDI-PhE/Al & 23.1 & 1.10 & 80.8 & 20.5 & 9 \\
\hline ITO/PTAA/perovskite/PCBM/C $60 / \mathrm{BCP} / \mathrm{Al}$ & 22.6 & 1.13 & 75 & 19.4 & 10 \\
\hline ITO/NiOx/perovskite/PCBM/Ca(acac) $)_{2} / \mathrm{Ag}$ & 23.45 & 1.08 & 79 & 20.15 & 11 \\
\hline ITO/PTAA:F4-TCNQ/PMMA/perovskite/PCBM/Bphen/Al & 22.59 & 1.114 & 73.93 & 18.61 & 12 \\
\hline $\begin{array}{c}\text { ITO/PTAA:F4- } \\
\text { TCNQ/PMMA/perovskite/PCBM/QAPDI/Al } \\
\end{array}$ & 23.87 & 1.130 & 76.18 & 20.55 & 12 \\
\hline ITO/PTAA/perovskite/P(BTI-PDI)/BCP/Ag & 23.3 & 1.12 & 79.1 & 20.8 & 13 \\
\hline ITO/PTAA/perovskite/PBTzTI/BCP/Ag & 22.94 & 1.136 & 80.1 & 20.86 & 14 \\
\hline $\mathrm{FTO} / \mathrm{NiO}_{\mathrm{x}} /$ perovskite/PCBM/C ${ }_{60} \mathrm{MPE}$-ionene/Ag & 22.15 & 1.10 & 79.15 & 19.28 & 15 \\
\hline ITO/P3CT-Na/perovskite/PC-2/C $60 / \mathrm{BCP} / \mathrm{Ag}$ & 22.49 & 1.11 & 0.821 & 20.50 & 16 \\
\hline ITO/PTAA/perovskite/PIL/C60/BCP/Cu & 22.54 & 1.158 & 81.93 & 21.39 & 17 \\
\hline ITO/PTAA:BCF/perovskite/PCBM/PDI-T/Ag & 22.73 & 1.153 & 80.56 & 21.06 & This \\
\hline ITO/PTAA:BCF/perovskite/PCBM/PDI-D/Ag & 20.15 & 1.130 & 75.25 & 17.13 & work \\
\hline
\end{tabular}

\section{References}

(1) Hu, Y. C., S. Zhang, L. Zhang, Y. Yuan, Z. Zhao, X. Chen, Y. Facile Approach to Perylenemonoimide with Short Side Chains for Nonfullerene Solar Cells. J. Org. Chem. 2017, 82, 5926-5931.

(2) Andre' Wicklein, A. L., Mathis Muth, and Mukundan Thelakkat*. Swallow-Tail Substituted Liquid Crystalline Perylene Bisimides: Synthesis and Thermotropic Properties. J. Am. Chem. Soc. 2009, 131, 14442-14453.

(3) Karuppuswamy, P.; Chen, H.-C.; Wang, P.-C.; Hsu, C.-P.; Wong, K.-T.; Chu, C.-W. The 3 D Structure of Twisted Benzo[ghi]perylene-Triimide Dimer as a Non-Fullerene Acceptor for Inverted Perovskite Solar Cells. ChemSusChem 2018, 11, 415-423.

(4) Jiang, K.; Wu, F.; Yu, H.; Yao, Y.; Zhang, G.; Zhu, L.; Yan, H. A perylene diimide-based electron transport layer enabling efficient inverted perovskite solar cells. J. Mater. Chem. A 2018, 6, 1686816873.

(5) Wang, R.; Jiang, K.; Yu, H.; Wu, F.; Zhu, L.; Yan, H. Efficient inverted perovskite solar cells with truxene-bridged PDI trimers as electron transporting materials. Mater. Chem. Front. 2019, 3, 2137-2142. 
(6) Yang, L.; Wu, M.; Cai, F.; Wang, P.; Gurney, R. S.; Liu, D.; Xia, J.; Wang, T. Restrained lightsoaking and reduced hysteresis in perovskite solar cells employing a helical perylene diimide interfacial layer. J. Mater. Chem. A 2018, 6, 10379-10387.

(7) Wang, H.; Yang, F.; Xiang, Y.; Ye, S.; Peng, X.; Song, J.; Qu, J.; Wong, W.-Y. Achieving efficient inverted perovskite solar cells with excellent electron transport and stability by employing a ladder-conjugated perylene diimide dimer. J. Mater. Chem. A 2019, 7, 24191-24198.

(8) Hou, Y.; Chen, W.; Baran, D.; Stubhan, T.; Luechinger, N. A.; Hartmeier, B.; Richter, M.; Min, J.; Chen, S.; Quiroz, C. O. R.; Li, N.; Zhang, H.; Heumueller, T.; Matt, G. J.; Osvet, A.; Forberich, K.; Zhang, Z.-G.; Li, Y.; Winter, B.; Schweizer, P.; Spiecker, E.; Brabec, C. J. Overcoming the Interface Losses in Planar Heterojunction Perovskite-Based Solar Cells. Adv. Mater. 2016, 28, 5112-5120.

(9) Jung, S.-K.; Heo, J. H.; Lee, D. W.; Lee, S.-H.; Lee, S.-C.; Yoon, W.; Yun, H.; Kim, D.; Kim, J. H.; Im, S. H.; Kwon, O. P. Homochiral Asymmetric-Shaped Electron-Transporting Materials for Efficient Non-Fullerene Perovskite Solar Cells. ChemSusChem 2019, 12, 224-230.

(10) Shao, Y.; Yuan, Y.; Huang, J. Correlation of energy disorder and open-circuit voltage in hybrid perovskite solar cells. Nat. Energy 2016, 1, 15001.

(11) Zhao, Z. Q.; You, S.; Huang, J.; Yuan, L.; Xiao, Z. Y.; Cao, Y.; Cheng, N.; Hu, L.; Liu, J. F.; Yu, B. H. Molecular modulator for stable inverted planar perovskite solar cells with efficiency enhanced by interface engineering. J. Mater. Chem. C 2019, 7, 9735-9742.

(12) Wang, H.; Song, J.; Qu, J.; Lian, J.; Qian, P.-C.; Wong, W.-Y. A novel perylene diimide-based zwitterion as the cathode interlayer for high-performance perovskite solar cells. J. Mater. Chem. A 2020, 8, 18117-18124.

(13) Shi, Y.; Chen, W.; Wu, Z.; Wang, Y.; Sun, W.; Yang, K.; Tang, Y.; Woo, H. Y.; Zhou, M.; Djurišić, A. B.; He, Z.; Guo, X. Imide-functionalized acceptor-acceptor copolymers as efficient electron transport layers for high-performance perovskite solar cells. J. Mater. Chem. A 2020, 8, 1375413762.

(14) Chen, W.; Shi, Y.; Wang, Y.; Feng, X.; Djurišić, A. B.; Woo, H. Y.; Guo, X.; He, Z. N-type conjugated polymer as efficient electron transport layer for planar inverted perovskite solar cells with power conversion efficiency of 20.86\%. Nano Energy 2020, 68, 104363.

(15) Zheng, T.; Zhou, H.; Fan, B.; Zhao, Y.; Jin, B.; Fan, L.; Peng, R. Designing conductive fullerenes ionene polymers as efficient cathode interlayer to improve inverted perovskite solar cells efficiency and stability. Chemical Engineering Journal 2021, 415, 128816.

(16) Jia, J.; Wu, F.; Zhu, L.; Yang, C. Unfused Electronic Acceptor-Based Polymers as Interfacial Materials for Efficient Inverted Perovskite Solar Cells. ACS Appl. Mater. Interfaces 2021, 13, 3332833334.

(17) Caprioglio, P.; Cruz, D. S.; Caicedo-Dávila, S.; Zu, F.; Sutanto, A. A.; Peña-Camargo, F.; Kegelmann, L.; Meggiolaro, D.; Gregori, L.; Wolff, C. M.; Stiller, B.; Perdigón-Toro, L.; Köbler, H.; Li, B.; Gutierrez-Partida, E.; Lauermann, I.; Abate, A.; Koch, N.; De Angelis, F.; Rech, B.; Grancini, G.; Abou-Ras, D.; Nazeeruddin, M. K.; Stolterfoht, M.; Albrecht, S.; Antonietti, M.; Neher, D. Bifunctional interfaces by poly(ionic liquid) treatment in efficient pin and nip perovskite solar cells. Energy Environ. Sci. 2021, 14, 4508-4522. 